\title{
RUBRIEKEN
}

REVIEW ESSAY

\section{Zoeken naar een evenwichtig veiligheidsbeleid: risicomanagement, onzekerheid en crises}

\author{
Sandra L. Resodihardjo
}

Besproken publicaties:

Power, M. (2004). The risk management of everything. Rethinking the politics of uncertainty. London: Demos.

Boutellier, H. (2013). The improvising society. Social order in a boundless world. The Hague: Eleven International Publishing.

Duin, M. van, Wijkhuijs, V., \& Jong, W. (Eds.). (2013). Lessen uit crises en minicrises 2012. Den Haag: Boom Lemma uitgevers.

In de afgelopen jaren is de verantwoordelijkheid voor het voorkomen en managen van crises steeds meer bij de overheid komen te liggen. Waar vroeger rampen nog konden worden weggezet als iets waar je toch niets aan had kunnen doen, worden rampen tegenwoordig gezien als voorkombaar (Power, 2004, p. 14). Mochten ze onverhoopt toch gebeuren, dan is de gedachte dat we de gevolgen ervan kunnen minimaliseren. Die verschuiving in hoe we tegen rampen en incidenten aankijken, zorgt ervoor dat de verwachtingen hooggespannen zijn als het gaat om overheidsoptreden ten aanzien van het voorkomen en managen van rampen. Alhoewel de overheid enige druk probeert te bieden tegen deze verwachtingen - door burgers bijvoorbeeld via reclame te wijzen op hun eigen verantwoordelijkheid om een noodpakket in huis te hebben voor het geval er wat gebeurt - blijft de verantwoordelijkheid voor veiligheid en risicomanagement primair bij de overheid liggen. Maar hoe gaat de overheid om met deze verantwoordelijkheid? Hoe gaat zij om met onzekerheden in de maatschappij en de mogelijke risico's die daarbij horen? En hoever moet zij gaan in het beschermen van haar burgers?

Sommige onderzoekers hebben een duidelijk beeld van hoe de overheid zou moeten reageren op veiligheidsvraagstukken. Zo zijn er auteurs die de overheid adviseren om haar veiligheidsbeleid te baseren op het voorzorgsprincipe. Deze aanpak vereist een proactieve overheid die niet alleen beleid maakt voor voorzienbare veiligheidsproblemen, maar ook voor onvoorzienbare veiligheidsproblemen (WRR, 2008, p. 18). Andere auteurs daarentegen waarschuwen de overheid dat zij niet moet doorslaan in haar wens veiligheidsrisico's te managen. De overheid heeft namelijk de neiging om na crises kostbare maatregelen te nemen die zouden moeten leiden tot voorkoming van deze crises in de toekomst - de zogenoemde risico-regelreflex. Aangezien geld maar één keer uitgegeven kan worden, dient de 
overheid bewuster keuzes te maken hoe dat geld te besteden: geeft zij geld uit aan een maatregel die maar marginaal de veiligheid verbetert of geeft zij het geld ergens anders aan uit (Helsloot, 2012)?

Naast publicaties waarin wordt ingegaan op hoe de overheid zou moeten omgaan met veiligheidsvraagstukken, zijn er ook tal van publicaties waarin alleen aandacht wordt besteed aan de manier waarop daadwerkelijk wordt omgegaan met specifieke veiligheidsproblemen. Deze publicaties variëren van historische overzichtswerken (bijv. De Keizer \& Roels, 2007) en diepgaande case-analyses (bijv. Vaughan, 1996) tot beschouwingen over wat er gebeurt na de crisis qua beleid (bijv. Lodge \& Hood, 2002) en verantwoordelijkheid (bijv. Boin, McConnell \&'t Hart, 2008).

In dit review essay worden drie toevoegingen aan de al talrijke literatuur op dit gebied besproken. Alle drie focussen ze op de vraag hoe de overheid omgaat met onveiligheid, onzekerheid en risico. Dit doen zij vanuit verschillende perspectieven. Power (2004) hanteert een historisch perspectief in zijn bespreking van de opkomst en uitbouw van risicomanagement alsmede de gevaren hiervan. Hij benadrukt daarbij dat de noodzaak om een mogelijke schuldvraag te vermijden kan leiden tot een wildgroei aan risicomanagement. Boutellier (2013) gebruikt een sociologisch-filosofisch perspectief om te duiden hoe de overheid omgaat met een maatschappij die alsmaar complexer en daarmee onzekerder is geworden. Van Duin, Wijkhuijs en Jong (2013) hanteren een praktisch en empirisch perspectief door op basis van twintig cases, waarin het optreden van de overheid wordt geanalyseerd, concrete handvatten te geven hoe om te gaan met crises en incidenten.

\section{De opkomst en consequenties van het managen van elk mogelijk risico}

Michael Power, verbonden aan de London School of Economics als hoogleraar en directeur van het Centre for the analysis of risk and regulation, heeft zijn inaugurele rede van 1999 omgevormd tot een publicatie, getiteld 'The risk management of everything. Rethinking the politics of uncertainty' (2004). Alhoewel het enige tijd geleden is dat dit stuk is gepubliceerd, wordt zijn essay om drie redenen toch meegenomen in deze review. Ten eerste geeft het helder de opkomst en uitbouw van risicomanagement weer - zeker voor jongere generaties (die onbekend zijn met crises zoals de val van Barings en de poging van Shell om het Brent Spar platform te dumpen in de Noordzee) is het goed te weten welke rol deze crises hierin hebben gespeeld. Ten tweede zijn de door Power opgeworpen vraagstukken nog steeds courant. En ten derde is dit essay gratis te downloaden voor geïnteresseerden. ${ }^{1}$

Powers publicatie is niet gericht op een specifiek publiek, maar moet meer worden gezien als een essay waarin hij vanuit een historisch perspectief duidelijk maakt wat risicomanagement is. Hij begint zijn essay met een historisch overzicht om uit te leggen hoe risicomanagement zo explosief heeft kunnen groeien. Risico- 
management komt voort uit de wens om twee tegenstrijdigheden uit de politieke realiteit met elkaar te verbinden. Enerzijds willen overheid en politici namelijk laten zien dat zij de situatie onder controle hebben, anderzijds is de werkelijkheid nu eenmaal zo complex en onzeker dat deze lastig te managen is. Door crises zoals de uitbraak van de gekkekoeienziekte is risicomanagement een kerntaak van de overheid geworden. In de loop der jaren is risicomanagement verder gegroeid aangezien we op steeds meer terreinen proberen risico's te managen. Tegenwoordig hebben we daarom te maken met het risk management of everything.

Power vervolgt zijn essay met een overzicht van wat risicomanagement inhoudt, beginnend met de overheid als risicomanager, de rol van risicoperceptie, communicatie en reputatie, de rol van regelgeving en beleid en hoe interne controle geregeld kan worden. Tevens gaat hij in op de relatie tussen risicomanagement en het afleggen van verantwoording.

Gezien het feit dat er al heel wat gepubliceerd is over risicomanagement, wordt in dit review essay niet zozeer ingegaan op wat risicomanagement inhoudt, maar op wat de meerwaarde van Powers werk is. Deze meerwaarde zit in het feit dat Power de lezer niet alleen (praktische) informatie verschaft, maar deze ook aan het denken zet. Dit doet hij aan de ene kant door de lezer vragen voor te leggen die hij niet altijd beantwoordt, maar die hij gebruikt om de lezer wakker te schudden en kritischer te laten kijken naar het fenomeen risicomanagement. Zo stelt hij onder meer de vraag wat risico eigenlijk is en waarom steeds meer zaken als een risico worden gedefinieerd.

Aan de andere kant benoemt Power een aantal ontwikkelingen. Zo wijst hij er bijvoorbeeld op dat interne controleprocedures tegenwoordig onderdeel zijn geworden van risicomanagement omdat interne controleprocedures kunnen helpen risico's te voorkomen. Deze procedures worden echter gekenmerkt door een aantal zwakheden zoals een interne focus waardoor men niet goed weet 'waarover het publiek nu eigenlijk gerustgesteld wil worden' (Power, 2004, p. 28). Daarnaast wordt de lezer bewust gemaakt van het feit dat de wens om alle risico's te managen heeft gezorgd voor de opkomst van secundair risicomanagement, oftewel reputatierisicomanagement. Immers, als primair risicomanagement faalt, doet zich een incident voor. Het incident toont de buitenwacht dat leidinggevenden het primaire risicomanagement onvoldoende beheersen. Dit kan tot reputatieschade leiden van personen en organisaties en resulteren in ontslag van een individu of de teloorgang van een organisatie. Om dat te voorkomen is reputatierisicomanagement noodzakelijk.

Power sluit zijn essay af met de boodschap dat het belangrijk is om de gevaren van risicomanagement te vermijden. Een gevaar is bijvoorbeeld dat primair risicomanagement gebruikt/misbruikt wordt om de reputatie te beschermen. Zo kan rapporteren een doel op zich worden om zo te bewijzen dat men actief bezig is geweest op het gebied van primair risicomanagement. Mocht er dan onverhoopt toch wat gebeuren, dan kan men zich hierachter verschuilen (secundair risicomanagement). Power adviseert om te streven naar een intelligente vorm van risicomanagement, waarbij onder meer ruimte is voor individuen om besluiten te nemen; besluiten waarvan men zich moet realiseren dat die gemaakt zijn met de 
kennis van toen en niet met de kennis van nu. Het is immers altijd makkelijk om achteraf te zeggen dat iedereen die crisis toch had kunnen zien aankomen. Maar de realiteit is dat op het moment dat er besluiten genomen moesten worden, de situatie veel onzekerder en weerbarstiger was.

\section{Improviserend omgaan met onzekerheid}

Onzekerheid en hoe hier mee om te gaan vormt ook de kern van Boutelliers boek 'The improvising society. Social order in a boundless world' (2013). Hans Boutellier, directeur van het Verwey-Jonker Instituut en bijzonder hoogleraar aan de VU, kijkt daarbij niet alleen naar onzekerheid op het gebied van veiligheid. Integendeel, vanuit een sociologisch-filosofisch perspectief kijkt hij naar de maatschappij als geheel, die door globalisering, individualisering, informatisering en de opkomst van het netwerkdenken wordt gekenmerkt door complexiteit. Die complexiteit zorgt ervoor dat men niet langer een goed overzicht heeft van wat er allemaal gaande is. Volgens Boutellier proberen ambtenaren wel om te gaan met die complexiteit, maar is er veel onzekerheid over hoe dit te doen. In Boutelliers optiek leidt deze onzekerheid tot de wens om meer grip te krijgen en dan met name grip op morele zaken (moral coherence) en op de manier waarop de maatschappij is ingericht (institutional design). Door normatieve richting te geven en de maatschappij daarop in te richten, kan er maatschappelijke orde ontstaan. Die orde zorgt voor rust.

Boutellier benadrukt dat deze orde niet statisch is. Door de eerdergenoemde complexiteit zijn er continu factoren, inzichten en ideeën die alles weer overhoop gooien. Continue improvisatie is daarom geboden om te komen tot georganiseerde vrijheid. Hier bedoelt hij een maatschappij mee die georganiseerd is in gemeenschappen en netwerken, waardoor burgers binnen de rule of law in vrijheid kunnen leven. Improvisatie resulteert daarmee in maatschappelijke orde.

Met enkele rake penstreken zet de auteur het fenomeen maatschappelijke onzekerheid neer. Na de opkomst van de risicomaatschappij hebben incidenten zoals 9/11 en de moord op Van Gogh burgers verder doen beseffen dat de risico's niet een ver-van-hun-bed-show zijn. De wens tot meer zekerheid en veiligheid is daarmee gegroeid, terwijl er grote onzekerheid bestaat over welke risico's er zijn en wanneer deze zich voordoen. Boutellier stelt dat die onzekerheid verder vergroot wordt doordat veel dingen die nu voor waar worden aangenomen, morgen niet meer waar hoeven te zijn door voortschrijdende inzichten. Deze fluïditeit gecombineerd met individualisering leidt ertoe dat mensen vooral voor zichzelf een leuk leven willen creëren, wat er soms toe kan leiden dat zij normoverschrijdend gedrag vertonen - of dit nu in de realiteit is of in de virtuele realiteit van internet. In het boek worden drie pogingen beschreven om met complexiteit om te gaan, namelijk op het gebied van civilisatie, veiligheid en burgerparticipatie. Gezien het thema van dit essay zal worden ingezoomd op het hoofdstuk over veiligheid. Startpunt van dit hoofdstuk is de stelling dat veiligheid een containerbegrip is geworden waaronder verschillende zaken vallen, van vuilnis op straat tot terrorisme. Om deze trend te begrijpen, wijst Boutellier er allereerst op dat als het gaat 
om criminaliteit, er een slingerbeweging gaande is tussen afstraffing enerzijds en compassie, rehabilitatie en resocialisatie anderzijds. Al enige tijd beweegt de slinger zich richting afstraffing, waarbij de roep om strengere straffen en een hardere aanpak van criminelen steeds dominanter wordt. Boutellier stelt dat dit onder meer het gevolg is van een andere kijk in de maatschappij op criminaliteit en grensoverschrijdend gedrag, waarbij het idee heerst dat een strengere aanpak gerechtvaardigd is omdat mensen ervoor kiezen om de criminaliteit in te gaan.

Boutellier schetst daarna hoe criminaliteit onderdeel is geworden van de risicomaatschappij. In 1993 definieerde de overheid criminaliteit als onveiligheid in de eerste 'Integrale Veiligheidsrapportage'. Volgens de auteur werden er door deze herdefiniëring drie nieuwe verbanden gelegd, namelijk tussen (1) criminaliteit en risico; (2) traditionele strafrechtelijke organisaties en overige organisaties; en (3) de gebeurtenis en de beleving daarvan. Aangezien criminaliteit de veiligheid van een samenleving negatief beïnvloedt, is criminaliteit onderdeel geworden van het risicomanagementdebat. In het kader van het voorzorgsprincipe is er in het veiligheidsbeleid een tendens waarneembaar naar eerder en strenger preventief optreden. Preventie en aanpak van criminaliteit alsmede overige veiligheidsvraagstukken zijn daarbij langzamerhand niet alleen meer een taak van traditionele justitiële organisaties, zoals de politie en het $\mathrm{OM}$, maar ook van andere publieke en private organisaties zoals woningcorporaties en beveiligingsbedrijven, waarbij de burgemeester, in het kader van integrale veiligheid, de rol van regisseur vervult. Gezien de complexiteit, zowel in de hoeveelheid veiligheidsonderwerpen als de hoeveelheid actoren betrokken bij de integrale veiligheid, spreekt men ook wel over veiligheidsnetwerken. Deze complexiteit wordt nog verder versterkt door de introductie van het woord veiligheid, waardoor subjectieve gevoelens onderdeel van het beleid zijn geworden - burgers moeten zich immers veilig kunnen voelen in hun eigen wijk en stad. Een manier om met deze complexiteit om te gaan is wetten en regelgeving te gebruiken om mensen op te voeden en hun de juiste moraal bij te brengen. Boutellier waarschuwt echter dat in combinatie met de securitization van de maatschappij dit ertoe kan leiden dat er een verschuiving plaatsvindt. 'Niet de inhoud van normen, maar de mate van hun effectiviteit - of nog beter, de mate waarin ze afgedwongen kunnen worden - wordt het doel van de veiligheidsaanpak' (Boutellier, 2013, p. 77).

In de rest van het boek beargumenteert Boutellier dat controle (via wetgeving en informele regelgeving) en vanzelfsprekende interactie tussen actoren (gebaseerd op vertrouwen) samen de morele grenzen vormen waarbinnen de overheid al improviserend op zoek gaat naar manieren om om te gaan met complexiteit.

Boutellier borduurt in dit boek voort op eerder werk. Hij gaat daarbij zowel beschrijvend als normatief te werk, waarbij hij gebruikmaakt van verschillende disciplines, zoals sociologie, filosofie, criminologie en politicologie. Het boek is expliciet bedoeld voor 'iedereen die zich zorgen maakt over de problemen in onze maatschappij en die een goed geïnformeerde participant wil zijn in de zoektocht naar oplossingen' (Boutellier, 2013, voorflap). Wil de lezer echter het optimale uit dit boek halen, dan is reflectie tijdens het lezen nodig. Boutellier beschrijft namelijk intrigerende concepten waarbij, zeker als hij op het snijvlak beschrijvend- 
normatief opereert, de lezer getriggerd wordt na te denken over hoe deze zelf tegenover het fenomeen van de improviserende maatschappij staat.

\section{Leren van crises}

Een boek van een geheel andere orde is 'Lessen uit crises en mini-crises 2012' onder redactie van Menno van Duin (lector aan het Instituut Fysieke Veiligheid/ Politieacademie en bijzonder lector aan de Hogeschool Utrecht), Vina Wijkhuijs (senior onderzoeker aan het Instituut Fysieke Veiligheid/Politieacademie) en Wouter Jong (adviseur crisisbeheersing bij het Nederlands Genootschap van Burgemeesters). Dit boek is sterk empirisch ingesteld door naast een inleidend hoofdstuk, twintig cases te analyseren waarbij de openbare orde en veiligheid in het geding kwamen. De cases variëren van traditionele rampen en crises (zoals dodelijke verkeersongelukken en problemen met voedselveiligheid) tot kleinere incidenten die kortstondig tot veel aandacht van de media en maatschappij leidden (zoals de stranding van de bultrug). Elk casehoofdstuk is opgebouwd volgens het volgende stramien: een foto en tweet van iemand die ter plekke was, een beschrijving van de gebeurtenissen, een beschrijving van het thema of dilemma dat in deze case speelde, en een analyse. Omdat thema's/dilemma's per casus variëren, wordt een rijke schakering aan analyses en lessen aan de lezer gepresenteerd. Het boek past daarmee bij een reeks van andere boeken waarin concrete aanknopingspunten voor handelen tijdens crises worden gegeven (vgl. Bestuurlijk Netwerk Crisisbeheersing, 2005 en 2007). Alhoewel het boek expliciet bedoeld is voor bestuurders en professionals betrokken bij veiligheid, zorgen de opzet en helderheid van het betoog ervoor dat het boek ook uiterst toegankelijk is voor iedereen die geïnteresseerd is in hoe de overheid omgaat met crises en incidenten. In het inleidende hoofdstuk leggen Van Duin, Wijkhuijs en Jong uit dat er bewust is gekozen voor deze selectie van cases. Klassieke crises zijn immers niet meer het enige type crisis waarmee men wordt geconfronteerd; afwijkende (mini-)crises waarbij een beroep wordt gedaan op de burgemeester, de veiligheidsregio en/of GRIP (gecoördineerde regionale incidentbestrijdingsprocedure) komen steeds vaker voor. Daarnaast is ervoor gekozen om cases te selecteren die variëren in de fase van crisismanagement die centraal stond; in sommige cases stond het managen van de crisis zelf centraal en in andere cases juist de na-fase (evaluatie-fase) of de nazorg. Het idee daarbij is dat de lezer op deze manier kennis kan opdoen die misschien nuttig kan zijn als de lezer te zijner tijd zelf met een soortgelijke crisis te maken krijgt.

Die lessen zijn niet alleen case-specifiek, maar ook breder te trekken. Naar aanleiding van het vergelijken van de cases stellen Van Duin, Wijkhuijs en Jong dat bepaalde bevindingen in meerdere cases terug te vinden zijn. Een aantal van deze bevindingen zal hier worden gepresenteerd.

Een bevinding betreft de vraag welke actoren betrokken zijn bij het managen van de crisis. Het antwoord daarop is afhankelijk van hoe het probleem wordt gedefinieerd. Daar komt bij dat sommige organisaties weliswaar officieel en daadwerkelijk betrokken zijn bij het crisismanagement, maar dat zij hun taak niet goed uit- 
oefenen waardoor andere actoren, zoals de burgemeester of de gemeente, extra werk op hun schouders krijgen.

Daarnaast blijkt uit de vergelijking van cases dat de ernst van een gebeurtenis niet alleen bepaald wordt door de hoeveelheid media-aandacht en het aantal doden en gewonden, maar ook door de mate van uniekheid van de gebeurtenis. Immers, 'naarmate de situatie meer bijzonder of afwijkend is, zal de ernst vaak sterker gevoeld worden' (Van Duin, Wijkhuijs, \& Jong, 2013, p. 18). Tevens speelt toeval een opvallende rol bij het bepalen van de ernst van een gebeurtenis. Zo waren bijvoorbeeld de effecten van een treinbotsing niet onmiddellijk duidelijk aangezien ieders aandacht bij het net gevallen kabinet lag.

In alle cases, groot of klein, speelde communicatie een cruciale rol. 'Als betrokkenen erin slagen het organisatorisch en communicatief aardig te doen, zal het crisismanagement in de perceptie van de buitenwereld veelal succesvol zijn verlopen' (Van Duin, Wijkhuijs, \& Jong, 2013, p. 20). Waar het qua communicatie bijvoorbeeld wat minder liep, was het opschalen naar GRIP-3; ten onrechte wordt deze opschaling door de media gezien als een bevestiging dat er een ramp is, terwijl er helemaal geen ramp hoeft te zijn. Het is daarom belangrijk dat actoren beter uitleggen dat GRIP-3 simpelweg betekent 'dat betrokkenen, in een logisch verband en voorzien van volwaardige ondersteuning, onder de formele leiding van de burgemeester (die natuurlijk ook bij lagere GRIP-niveaus de formele leiding heeft) aan het werk gaan om de (soms potentieel dreigende) situatie zo goed mogelijk het hoofd te bieden' (Van Duin, Wijkhuijs, \& Jong, 2013, p. 21).

Een andere interessante bevinding ten aanzien van communicatie is dat niet iedereen dezelfde communicatiedoelen wil bereiken tijdens een crisis. Belangen van bedrijven lopen bijvoorbeeld niet altijd synchroon met de belangen van de overheid, waardoor woordvoerders van verschillende organisaties niet op één lijn zitten. Daarnaast kunnen belangengroepen de crisis gebruiken om hun standpunt nog eens goed naar voren te brengen. De auteurs waarschuwen dat dit laatste nadelig kan uitwerken tijdens het managen van een crisis omdat de mediaervaring van belangengroepen dusdanig kan zijn, dat zij in staat zijn de crisis zo te framen dat de overheid in een negatief daglicht komt te staan. Het crisismanagement van de overheid wordt daardoor gecompliceerder, omdat zij zich ook nog eens moet verdedigen tegen allerlei aantijgingen.

De cases laten daarnaast zien dat de aloude truc van het instellen van een commissie na of tijdens een crisis zodat men even geen vragen meer hoeft te beantwoorden, niet altijd meer werkt. Media gaan soms gewoon door met het vergaren van nieuws. Als gevolg daarvan is het lastig voor autoriteiten om een commissierapport te negeren of tegen te spreken. De auteurs adviseren daarom om (1) goed beslagen ten ijs het commissierapport tegemoet te treden (eventueel door zelf nog een interne commissie hierop te zetten) waardoor adviezen en vragen beter gepareerd kunnen worden; en om (2) geen radiostilte in te lassen (ook al is de externe commissie bezig om onderzoek te doen), maar om de burger te blijven informeren over wat er gaande is, zodat het vertrouwen van de burger in de overheid weer hersteld kan worden.

Een laatste bevinding die hier genoemd wordt, is de roep om nieuwe, extra of aangescherpte procedures naar aanleiding van een crisis. De auteurs wijzen erop dat 
men zich bewust moet blijven van het feit dat het niet mogelijk is om (1) op alle mogelijke calamiteiten voorbereid te zijn, en (2) alles vooraf netjes in plannen en regels te gieten.

\section{Conclusie}

Dit essay begon met het benoemen van de trend waarbij de overheid steeds meer verantwoordelijk is voor het voorkomen en managen van crises. Het daarbij aangehaalde debat tussen voor- en tegenstanders van het voorzorgsprincipe maakt duidelijk dat de overheid een belangrijke maatschappelijke vraag moet beantwoorden: hoe ver moet de overheid gaan in het beschermen van haar burgers?

De drie besproken stukken laten vanuit drie verschillende perspectieven zien dat de overheid hierbij continu aan het balanceren is om een goed evenwicht te vinden, maar dat dat evenwicht ook weer snel kan worden verstoord. Zo kan dat evenwicht verstoord worden doordat wat onder veiligheid wordt verstaan, steeds uitgebreid wordt. Doordat criminaliteit tegenwoordig als een veiligheidsprobleem wordt gedefinieerd, is deze nu onderdeel geworden van de risicomaatschappij (Boutellier, 2013). Aangezien rampen en crises nu vaker als voorkombaar worden gedefinieerd, zijn zij ook de verantwoordelijkheid van de overheid geworden (Power, 2004). En de manier waarop de crisis wordt gedefinieerd, bepaalt onder meer welke (overheids)actoren betrokken zijn bij het managen van de crisis (Van Duin, Wijkhuijs, \& Jong, 2013).

Al improviserend probeert de overheid een goede balans te vinden in hoe ver zij moet gaan om haar burgers te beschermen (Boutellier, 2013). Relativeren en ruimte geven aan besluitnemers is daarbij belangrijk: besluiten die in het verleden zijn genomen, moeten niet worden dood geanalyseerd met de kennis van nu (Power, 2004). Communicatie speelt hierbij een belangrijke rol, aangezien deze het crisismanagement in goede banen kan leiden en het vertrouwen met de burger kan herstellen (Van Duin, Wijkhuijs, \& Jong, 2013).

Bij het zoeken naar een balans dient men zich te realiseren dat procedures en regelgeving geen panacee zijn voor onveiligheid en risico. Zo waarschuwt Power (2004) er onder andere voor dat secundair risicomanagement (het beschermen van de eigen reputatie) kan leiden tot een wildgroei van primair risicomanagement omdat men zich wil indekken via bijvoorbeeld rapporten waaruit blijkt dat men aan primair risicomanagement heeft gedaan. Boutellier (2013) wijst op het gevaar dat de inhoud van wet- en regelgeving op het gebied van veiligheid niet wordt ingegeven door normen waarvan men graag wil dat deze gevolgd worden, maar door de wens om met regels te komen die goed afgedwongen kunnen worden. Van Duin, Wijkhuijs en Jong (2013) benadrukken dat niet alles in regels te vatten is en dat men dit ook niet moet willen. 


\section{Literatuur}

Bestuurlijk Netwerk Crisisbeheersing. (2005). Als dat maar goed gaat. Bestuurlijke ervaringen met crises. Enschede: Bestuurlijk Netwerk Crisisbeheersing.

Bestuurlijk Netwerk Crisisbeheersing. (2007). Als het dan tóch gebeurt. Bestuurlijke ervaringen met crises. Enschede: Bestuurlijk Netwerk Crisisbeheersing.

Boin, A., McConnell, A., \& 't Hart, P. (2008). Governing after crisis. The politics of investigation, accountability and learning. Cambridge: Cambridge University Press.

Boutellier, H. (2013). The improvising society. Social order in a boundless world. The Hague: Eleven International Publishing.

Duin, M. van, Wijkhuijs, V., \& Jong, W. (2013). Leren van dilemma's: rode draden uit de casus. In M. van Duin, V. Wijkhuijs, \& W. Jong (Eds.), Lessen uit crises en mini-crises 2012 (pp. 10-34). Den Haag: Boom Lemma uitgevers.

Helsloot, I. (2012). Veiligheid als (bij)product. Over beleidsontwikkeling in interactie tussen bestuurders, adviseurs en narrige burgers. Nijmegen: Radboud Universiteit Nijmegen.

Keizer, M. de, \& Roels, S. C. (2007). Staat van veiligheid. De Nederlandse samenleving sinds 1900. Zutphen: Nederlands Instituut voor Oorlogsdocumentatie, p/a Walburg Pers.

Lodge, M., \& Hood, C. (2002). Pavlovian policy responses to media feeding frenzies? Dangerous dogs regulation in comparative perspective. Journal of Contingencies and Crisis Management, 10(1), 1-13.

Power, M. (2004). The risk management of everything. Rethinking the politics of uncertainty. London: Demos.

Vaughan, D. (1996). The Challenger launch decision. Risky technology, culture and deviance at NASA. Chicago: University of Chicago Press.

WRR (Wetenschappelijke Raad voor het Regeringsbeleid). (2008). Onzekere veiligheid. Verantwoordelijkheden rond fysieke veiligheid. Amsterdam: Amsterdam University Press. 